American Journal of Applied Sciences 6 (1): 172-178, 2009

ISSN 1546-9239

(C) 2009 Science Publications

\title{
A Combining Ability Analysis of Cassava Manihot esculenta Crantz Genotypes to Anthracnose Disease
}

\author{
${ }^{1,2,3}$ O.F. Owolade, ${ }^{1}$ A.G.O. Dixon, ${ }^{3}$ S.R. Akande and ${ }^{3}$ S.A. Olakojo \\ ${ }^{1}$ International Institute of Tropical Agriculture (IITA), Ibadan, Nigeria \\ ${ }^{2}$ DeparTiment of Crop Protection, University of Agriculture, Abeokuta, Nigeria \\ ${ }^{3}$ Institute of Agricultural Research and Training, Ibadan, Nigeria
}

\begin{abstract}
Cassava Anthracnose Disease (CAD) caused by Colletotrichum gloeosporioides $\mathrm{f}$ sp. manihotis has been recognized as one of the major economic disease of cassava in all the cassava growing regions of Africa. Little information is available on the resistance of cassava to $\mathrm{C}$. gloeosporioides f sp. manihotis. This study was conducted to determine the relative importance of general (GCA) and specific (SCA) combining ability, maternal and non-maternal reciprocal effects on resistance to $C$. gloeosporioides $\mathrm{f}$ sp. manihotis in selected cassava genotypes. A complete diallel mating scheme including reciprocals of nine resistant and susceptible genotypes of cassava were evaluated in the field over a period of two planting seasons. The combining ability analysis revealed that both the additive and nonadditive gene effects were present. Crosses between the resistant lines and susceptible genotypes showed intermediate disease reaction to CAD suggesting a polygenic system of resistance to the disease. The significant maternal and specific reciprocal differences among the parents and crosses indicated that maternal and/or cytoplasmic inheritance is involved in the reaction of cassava genotypes to Colletotrichum gloeosporioides $\mathrm{f} s \mathrm{~s}$ manihotis. The significant genotype X environment interaction suggested lack of stability in the development of lesions/cankers on cassava stems. Therefore, recurrent selection would be appropriate for accumulating genes for resistance to $\mathrm{CAD}$ in cassava and progeny performance may not be based on their parents performance $\sec ^{-1}$.
\end{abstract}

Key words: CAD, GCA specific combining ability, SCA specific combining ability

\section{INTRODUCTION}

The tropical root crop cassava (Manihot esculenta Crantz) is the third most important source of calories for human food in the tropics after rice and maize. Over 600 million people depend on cassava in Africa, Asia, and Latin America. Cassava is grown by poor farmers, many of them are women. For these people, the crop is vital for both food security and income generation ${ }^{[1]}$. In spite of the importance of this crop as a famine and food security plant, it is constantly threatened by production constraints such as drought, low yielding local cultivars, lack of good quality planting materials, land tenure, pests and diseases ${ }^{[2]}$.

Of all the diseases found on cassava, Cassava Anthracnose Disease (CAD) caused by Colletotrichum gloeosporioides Penz $\mathrm{f} \mathrm{sp}$. manihotis $\mathrm{Chev}$ is the most important fungal disease of cassava in the field ${ }^{[3]}$. The most outstanding effect of the disease is its ability to cause severe stem damage causing canker on stem, wilting of leaves and diebacks. Badly infected stems become brittle and break easily under strong winds. The overall effect of these is the reduction in yield and in the amount of healthy plantable stems available to the farmers. The frequency with which the disease is encountered in cassava in African has been a matter of concern to many workers ${ }^{[4,5]}$ reported that between 80 $90 \%$ of local cultivars were rated as severely infected in Zaire and Congo respectively ${ }^{[6]}$ also observed that the causal organism of CAD was found on cassava stems from all the humid and the sub-humid agro-ecological zones of Nigeria, just as ${ }^{[7]}$ reported a high incidence of $\mathrm{CAD}$ across the countries of the rainforest and transition forest zones. In spite of all these reports of widespread distribution of CAD in Africa and the progress made in resistance breeding to Africa Cassava Mosaic Virus (ACMV), Cassava Bacterial Blight ${ }^{[8,9]}$ $\mathrm{CAD}$ is rarely taken into consideration in the breeding programme. The spotlight has, therefore, shifted to host plant resistance since it is acknowledged that, resistant cassava varieties could potentially form the basis of sustainable management strategies for cassava

Corresponding Author: O.F. Owolade, Institute of Agricultural Research and Training, PMB 5029, Ibadan, Oyo State, Nigeria 
diseases $^{[8,9,10]}$. The selection of resistant varieties and continuous breeding programme for disease resistance appears to be the efficient means of controlling CAD. Although little work has been done on resistance to CAD and determination of mode on inheritance. Studies in these areas will assist the breeder in formulating an efficient strategy for incorporating the resistant genes into high yielding improved and stable varieties. The overall objective of this work is to contribute to the development of stable anthracnose resistance in cassava. The specific objective of this study was to evaluate the relative importance of general and specific combining ability for resistance to CAD.

\section{MATERIALS AND METHODS}

Genetic experiments: The study was carried out on the experimental fields of the International Institute of Tropical Agriculture (IITA) at Ibadan in Nigeria. The genetic materials were evaluated using the complete diallel mating Scheme during 2004 and 2005 growing seasons. The genotypes were selected based on plant vigour (PV), Flowering Ability (FA) and Sprouting Ability (SA).

All possible crosses involving 9 parents with various degrees of resistance to CAD, (resistant, moderately resistant and susceptible varieties) were made on IITA research field in Ubiaja, Edo State, Nigeria in 2002 by hand pollination and the seeds were made available by cassava breeding unit at IITA for the study. The seeds were planted in pots in nursery prior to transplanting in the field, and watered twice daily for three weeks, and then once a day until the seedlings were established. Established seedlings were transplanted in the field at the same time to produce woody cuttings for the study. Mature stakes $(25 \mathrm{~cm}$ long) of the parents were planted at the beginning of the rainy season (June 2003). A randomized complete block design with three replicates was used. Each plot consisted of a minimum of 40 plants spaced $0.5 \mathrm{~m}$ apart in rows (ridges $30 \mathrm{~cm}$ high and $10 \mathrm{~m}$ long) and was spaced $1 \mathrm{~m}$ apart, giving a plant population of 20,000 plants per hectare. No fertilizer or herbicide was applied during the course of the experiment, and hand weeding was done when necessary. The parents and their $\mathrm{F}_{1}$ 's hybrids were evaluated under rain fed conditions in an area known for CAD epidemics in the 2004 and 2005 planting seasons at IITA's research farm in Ibadan, Nigeria, for their reactions to CAD 12 MAP. The improved cassava genotypes TMS I30572 (highly susceptible), TMS 91/02324 (moderately resistant), a moderately resistant landrace TIME 117 (Isunkankiyan) and a susceptible landrace TIME 1 (Antiota) were included as checks.

Individual plants were examined for symptom severity using the parameters and method as adopted by $^{[11]}$.

Genotypes were partitioned into variation due to lines (parents and crosses) and checks using the GLM procedure in Statatistical Analysis System (SAS). Analysis of variance for the crosses was based on Griffing's method 2, model 1 for fixed genotypes ${ }^{[12]}$ and the linear model ${ }^{[13]}$. The analysis was performed on individual environments using the diallel-SAS programme written by ${ }^{[14]}$ and a combined analysis over environments using the diallel-SAS programme written by ${ }^{[15]}$.

The genaral linear model for an individual environment was:

$$
y i j k=\mu+g+g j+s i j+r i j+b k+C i j k
$$

where, yijk was the response of the kth observation in the ith environment of the plant, $\mu$ was general mean, gi the general combining ability (GCA) of the ith parent, gj the general combining ability (SCA) of the jth parent, sij the specific combining ability associated with the ith and jth cross, rij the reciprocal effects associated with ijth cross. bk the effect of the kth replicate and Cijk is the error associated with each observation.

The general linear model for the combined analysis was:

$$
Y i j k l=\mu+g i+g j+s i j+l k+b l(k+g l i k+g l j k+s l i j k+C i j l
$$

In this model, Yijkl was the observed response to CAD across the two seasons, $\mu$, gi, gj, and sij and its partitions $\mathrm{mi}$ and $\mathrm{nj}$ were for the individual season analysis. The effect $\mathrm{lk}$ was the effect of the kth season, bl (k) the effect of the lth replicate within the kth season. The effect glik was the general combining ability of the ith parent in the season, gljk the general combining ability of the jth parent in the kth environment and slijk the specific combining ability associated with the ijth cross in the season.

Genetic components of the variation associated with GCA and SCA effects were estimated from their respective expected means squares. The ratio of these components was computed to estimate the relative importance of GCA in predicting progeny performance. The GCA and SCA effects and their standard errors were estimated according to ${ }^{[13]}$ Pearson correlations 
using line and top cross means were calculated to compare line and top cross

\section{RESULTS AND DISCUSSION}

The analysis of variance for $9 \times 9$ diallel involving seven improved cassava clones (I30001, I30555, I30572, I60142, and I90257) and two landraces (TIME8 and TIME-9) is presented in Table 1. There were variations $(\mathrm{p}<0.05)$ among the environments and genotypes in the combined analysis for CAD canker counts. Moreover, the contrast parent $\times$ crosses (the test for average heterosis) was significant for both the combined and individual environment. The Griffing analysis of variance for the crosses revealed significant GCA, SCA, maternal and specific reciprocal effects in both the combined and individual environments. The Crosses X E, GCA X E, SCA X E, REC X E and M X $E$ effects were also significant for CAD canker counts. The maternal effects among the parents were significant just as the specific reciprocal effects among their crosses were also significant $\mathrm{p}<0.01$. The genetic ratio, additive variance to total variance for the diallel analysis was $0.48,0.41$ and 0.43 for year 2004, 2005 and the combined environments respectively. There were significant $(\mathrm{p}<0.05)$ relationships between the 9 parents performance per se and their GCA effects in individual environment and combined environments. ( $\mathrm{r}$ $=0.55^{* *}$ for $2004, \mathrm{r}=0.67 * *$ and $\mathrm{r}=0.41 * *$ for combined environment). However, the line performances of the parents were not significantly correlated to their mean top cross performance $(r=0.04$ for 2003, $r=0.15$ for 2004 and .0 .29 in the combined environments. GCA and SCA sums of squares accounted for $43.44 \%$ and $56.56 \%$ of variation among crosses in the combined year respectively. GCA accounted for 58.22 and $61.04 \%$ in year 2004 and 2005 respectively, while the SCA accounted for 41.84 and $38.95 \%$ variations among the crosses in year 2004 and 2005.

The estimates of GCA effects of each parent for total number of cankers/plant on cassava stems are presented in Table 2. Only negative values indicated contributions towards resistance, while positive significant values suggest a contribution towards susceptibility. The resistant lines I63397 had significant negative GCA effects in both Ibadan environments and

Table 1: Diallel analysis of variance for anthracnose disease of cassava

\begin{tabular}{|c|c|c|c|c|c|c|}
\hline \multicolumn{3}{|c|}{ Sources of variation } & $\mathrm{df}$ & Combined & 2004 & 2005 \\
\hline \multicolumn{3}{|c|}{ Reps } & 2 & $15.45^{\prime}$ & $14.0^{\prime}$ & $13.23^{\prime}$ \\
\hline \multicolumn{3}{|l|}{ Environment (E) } & 1 & $3636^{* * *}$ & & \\
\hline \multicolumn{3}{|l|}{ Reps (E) } & 4 & $23.85^{\prime}$ & & \\
\hline \multirow[t]{13}{*}{ Genotypes (G) } & & & 80 & $143.36 * *$ & $400.5 * *$ & $224.7 * *$ \\
\hline & Parent $(\mathrm{P})$ & & 8 & $87.67 * *$ & $204.00 * *$ & $154.2 * *$ \\
\hline & Cross (C) & & 71 & $137.24 * *$ & $214.26 * *$ & $225.04 * *$ \\
\hline & & SCA & 27 & $405.49 * *$ & $415.06 * *$ & $344.37 * *$ \\
\hline & & GCA & 8 & $156.40 * *$ & $139.50 * *$ & $165.1 *$ \\
\hline & & Maternal & 8 & $160.70 * *$ & $192.04 * *$ & $178.42 * *$ \\
\hline & & Reciprocal & 36 & $32.55 * *$ & $66.13 * *$ & $80.15^{* *}$ \\
\hline & $\mathrm{P} \times \mathrm{C}$ & & 1 & $39.42 *$ & $85.00 * *$ & $60.40 * *$ \\
\hline & CXE & & 71 & $49.55^{* *}$ & & \\
\hline & & GCA X E & 8 & $45.60^{* * *}$ & & \\
\hline & & SCA X E & 27 & $126.57 * *$ & & \\
\hline & & REC X E & 36 & $24.82^{\prime}$ & & \\
\hline & & M X E & 8 & $64.73^{* *}$ & & \\
\hline Error Pooled & & & 284 & $25.49^{\prime}$ & 17.05' & $33.93^{\prime}$ \\
\hline
\end{tabular}

*, ** Significantly different from zero at 0.05 and 0.01 probability levels respectively

Table 2: Estimates of general combining ability effects for $9 \times 9$ diallel analysis of resistance to CAD

\begin{tabular}{|c|c|c|c|c|c|c|}
\hline \multirow[t]{2}{*}{ Clones } & \multicolumn{2}{|c|}{ Combined Environment } & \multirow{2}{*}{$\begin{array}{l}2004 \\
\text { LSM }\end{array}$} & 2005 & \multirow[b]{2}{*}{ LSM } & \multirow[b]{2}{*}{ GCA } \\
\hline & LSM* $^{*}$ & GCA & & GCA & & \\
\hline I30001 & 9.25 & 0.632 & 10.00 & 0.874 & 8.50 & 3.080 \\
\hline I30555 & 20.50 & $4.680 * *$ & 20.50 & $6.026^{* * *}$ & 20.50 & $5.270 * *$ \\
\hline I30572 & 21.25 & 0.017 & 20.00 & 1.848 & 22.50 & 1.764 \\
\hline I60142 & 13.75 & -0.580 & 22.50 & 0.650 & 7.00 & $-2.520 * *$ \\
\hline I63397 & 4.75 & $-3.200 * *$ & 0.50 & $-3.438^{* *}$ & 9.00 & $-2.504 * *$ \\
\hline I90257 & 18.75 & -0.680 & 12.00 & -1.086 & 25.50 & 1.960 \\
\hline I4(2) 1425 & 16.00 & $-2.670 * *$ & 17.00 & $-2.570 * *$ & 15.00 & -0.504 \\
\hline TIME 8 & 14.00 & $-2.890 * *$ & 9.00 & $-4.082 * *$ & 19.00 & $-2.280 * *$ \\
\hline TIME 9 & 11.00 & -0.140 & 13.00 & $-2.750 * *$ & 9.00 & -0.504 \\
\hline SE (gi-gj) & & 1.983 & & 1.840 & & 1.672 \\
\hline
\end{tabular}

*, ** Significantly different from zero at 0.05 and 0.01 probability levels respectively *LSM $=$ least Square means 
in the combined environment showing its capacity to transmit resistance. The two landraces used in this study TIME-8 and TIME-9, which was susceptible to CAD, exhibited negative GCA in year 2004 and 2005 and across the environments. However, the susceptible improved clone I30555 had significant and positive GCA in all the environments. Susceptible improved clone 190257 had a non-significant negative GCA effect across the environments. The moderately susceptible improved clone $\mathrm{I} 30001$ had significant and positive GCA effects in the Ibadan 2005 environments. The highly susceptible improved clone I30572 had significant negative GCA.

The estimates of least square means, SCA and reciprocal effects of the diallel crosses is presented in Table 3. The crosses and their reciprocals manifested varying degree of resistance to CAD in the different environments. The crosses I60142×I63397, I60142×I90257, I60142×I4 (2) 1425, I60142×TIME8 ,

Table 3: Estimates of specific combining ability effects and reciprocal effects for 9 X 9 Diallel Analysis of Resistance to CAD

\begin{tabular}{|c|c|c|c|c|c|c|c|}
\hline \multirow[b]{2}{*}{ Cross } & \multicolumn{2}{|c|}{ Combined } & \multicolumn{2}{|l|}{2004} & \multicolumn{2}{|l|}{2005} & \multirow[b]{2}{*}{ Effects Environment } \\
\hline & LSM & SCA & LSM & SCA & LSM & SCA & \\
\hline$\overline{\mathrm{I} 3000 \mathrm{I} \times \mathrm{I} 30555}$ & 16.00 & $-3.53^{*}$ & 23.50 & $-5.28 * *$ & 8.50 & $-3.07 * *$ & SCA \\
\hline I3000IXI30572 & 10.50 & $-6.56^{* *}$ & 19.00 & $-11.62 * *$ & 4.00 & $-2.49 *$ & SCA \\
\hline I3000IXI60142 & 15.25 & $10.80 * *$ & 22.00 & $12.47 * *$ & 8.50 & 4.58 & SCA \\
\hline I3000IXI63397 & 9.50 & 2.94 & 9.00 & $-4.47 * *$ & 10.0 & 4.25 & SCA \\
\hline I3000I $\times I 90257$ & 8.50 & -0.35 & 15.00 & $-2.09 *$ & 2.00 & $-4.30 * *$ & SCA \\
\hline I3000IXI4 (2)1425 & 11.00 & 2.15 & 12.00 & -1.44 & 10.00 & 4.24 & SCA \\
\hline I3000IXTime-8 & 4.75 & $-3.84 * *$ & 0.500 & $-9.31 * *$ & 9.00 & $-3.71 * *$ & SCA \\
\hline I3000IXTime-9 & 14.25 & 1.07 & 22.00 & $-6.87 * *$ & 6.50 & 0.74 & SCA \\
\hline $\mathrm{I} 30555 \times \mathrm{I} 30572$ & 12.25 & $-3.51 * *$ & 21.00 & $-5.81 * *$ & 3.50 & $-3.23 * *$ & SCA \\
\hline I30555×I60142 & 16.25 & 2.11 & 25.00 & $-5.68 * *$ & 7.50 & 0.09 & SCA \\
\hline I30555×I63397 & 14.75 & 2.46 & 22.50 & 4.16 & 6.00 & -0.70 & SCA \\
\hline $\mathrm{I} 30555 \times \mathrm{I} 90257$ & 20.00 & 0.71 & 36.50 & 4.16 & 3.50 & $-3.66 * *$ & SCA \\
\hline $\mathrm{I} 30555 \times \mathrm{I} 4(2) 1425$ & 12.50 & -0.73 & 25.00 & 3.54 & 0.50 & -1.21 & SCA \\
\hline I30555×Time- 8 & 6.63 & $-2.85 * *$ & 13.20 & $-10.31 * *$ & 0.50 & -2.41 & SCA \\
\hline I30555×Time- 9 & 10.00 & -0.87 & 18.50 & $-8.12 * *$ & 1.50 & -1.58 & SCA \\
\hline I30572×I60142 & 7.25 & $-5.60 * *$ & 7.00 & $-14.43 * *$ & 7.50 & $-2.86^{*}$ & SCA \\
\hline I30572×I63397 & 10.00 & 3.27 & 19.50 & -1.09 & 0.50 & -0.65 & SCA \\
\hline I30572×I90257 & 21.25 & 0.50 & 36.50 & -0.72 & 6.00 & $6.60^{* * *}$ & SCA \\
\hline I30572×I4(2)1425 & 10.00 & 3.24 & 14.00 & $-8.31 * *$ & 0.50 & 0.09 & SCA \\
\hline I30572×Time- 8 & 21.25 & 7.14 & 18.50 & 8.57 & 0.50 & $7.30 * *$ & SCA \\
\hline I30572×Time-9 & 7.25 & 0.67 & 17.50 & $-5.99 * *$ & 0.50 & -1.40 & SCA \\
\hline I60142×I63397 & 0.50 & $-4.24 * *$ & 0.50 & $-3.97 *$ & 0.50 & -0.20 & SCA \\
\hline I60142×I90257 & 0.50 & $-5.93 * *$ & 0.50 & $-13.84 * *$ & 0.50 & -1.40 & SCA \\
\hline $\mathrm{I} 60142 \times \mathrm{I} 4(2) 1425$ & 0.50 & $-4.82 * *$ & 0.50 & $-12.43 * *$ & 0.50 & -1.03 & SCA \\
\hline I60142×Time-8 & 1.25 & $-3.58 * *$ & 2.00 & -2.06 & 0.50 & -0.90 & SCA \\
\hline I60142XTime-9 & 9.25 & 2.37 & 18.00 & 0.13 & 0.50 & 0.79 & SCA \\
\hline I63397×I90257 & 8.25 & 5.07 & 11.50 & 1.97 & 6.00 & $4.62 * *$ & SCA \\
\hline I63397XI4(2)1425 & 1.25 & $-3.55 * *$ & 2.00 & $-6.62 * *$ & 0.50 & $-3.05 * *$ & SCA \\
\hline I63397×Time-8 & 2.25 & $-4.58 * *$ & 4.00 & $-7.25 * *$ & 0.50 & $-4.51 * *$ & SCA \\
\hline I63397×Time-9 & 16.25 & 5.39 & 26.50 & 3.94 & 6.00 & -1.06 & SCA \\
\hline $\mathrm{I} 90257 \times \mathrm{I} 4(2) 1425$ & 4.00 & -1.56 & 7.00 & $-9.04 * *$ & 1.00 & 0.67 & SCA \\
\hline I90257×Time-8 & 18.50 & 2.54 & 24.00 & 0.13 & 12.50 & $-3.53 * *$ & SCA \\
\hline I90257×Time-9 & 1.00 & $-4.12 * *$ & 1.50 & $-8.68 * *$ & 0.50 & $6.87 * *$ & SCA \\
\hline I4(2)1425XTime- 8 & 0.75 & -0.09 & 1.00 & $-4.72 * *$ & 0.50 & -1.83 & SCA \\
\hline I4(2)1425XTime-9 & 12.75 & $-4.98 * *$ & 21.00 & $4.47 * *$ & 4.50 & $-4.82 * *$ & SCA \\
\hline Time- $8 \times$ Time- 9 & 7.50 & $-2.71 *$ & 14.50 & $-3.41 * *$ & 0.50 & $-3.33 * *$ & SCA \\
\hline
\end{tabular}

190257×TIME-9, I4 (2) 1425×TIME-8 were highly resistant across the environment and manifested significant and negative SCA effects. Crosses I30001× TIME-8, I63397×I4 (2) 1425, I63397×TIME-8 and TIME- $8 \times$ TIME-9 (from two susceptible parents) were also resistant to $\mathrm{CAD}$ and had negative SCA effects across environments. Negative specific reciprocal effects for resistance to $\mathrm{CAD}$ were significant for crosses TIME-8×I60142, TIME-8×I63397 which were reciprocal crosses of highly resistant crosses with significant negative SCA effects. The moderately resistant crosses I30555×TIME-8 and I30555×TIME-9 also exhibited significant negative SCA across the environment. The susceptible crosses I30001×I30555, $\mathrm{I} 30001 \times \mathrm{I} 30572$ and $\mathrm{I} 30555 \times \mathrm{I} 30572$ also had significant negative SCA effects. The susceptible cross I30001 $\times$ I60142 was detected to have significant positive SCA effects. 
Am. J. Applied Sci., 6(1): 172-178, 2009

Table 3: Continued

\begin{tabular}{|c|c|c|c|c|c|c|c|}
\hline \multirow[b]{2}{*}{ Cross } & \multicolumn{2}{|c|}{ Combined } & \multicolumn{2}{|l|}{2003} & \multicolumn{2}{|l|}{2004} & \multirow[b]{2}{*}{ Effects Environment } \\
\hline & LSM & SCA & LSM & SCA & LSM & SCA & \\
\hline $\mathrm{I} 30555 \times \mathrm{I} 30001$ & 9.50 & 1.50 & 17.0 & 3.25 & 2.00 & 0.50 & Recip. \\
\hline $\mathrm{I} 30572 \times \mathrm{I} 30001$ & 5.25 & 2.50 & 10.0 & 4.50 & 0.5 & 1.00 & Recip. \\
\hline $\mathrm{I} 30572 \times \mathrm{I} 30555$ & 14.50 & 1.88 & 25.0 & -2.22 & 4.00 & 3.25 & Recip. \\
\hline I60142×30001 & 22.00 & -3.75 & 42.0 & -10.0 & 2.00 & 1.75 & Recip. \\
\hline I60142×I30555 & 10.75 & 1.38 & 21.0 & 2.40 & 0.5 & 0.75 & Recip. \\
\hline $\mathrm{I} 60142 \times \mathrm{I} 30572$ & 6.00 & 2.25 & 6.00 & 0.75 & 6.00 & 0.50 & Recip. \\
\hline I63397×30001 & 6.25 & 0.50 & 12.00 & -1.50 & 0.5 & 2.00 & Recip. \\
\hline I63397×I30555 & 4.50 & 2.25 & 7.00 & 7.51 & 2.00 & 3.75 & Recip. \\
\hline I63397×I30572 & 6.00 & 0.85 & 11.00 & 4.25 & 1.00 & 2.50 & Recip. \\
\hline I63397×I60142 & 11.25 & $-11.50 * *$ & 21.50 & $-10.75^{* *}$ & 1.00 & $-11.50 * *$ & Recip. \\
\hline I90257×30001 & 8.25 & 0.25 & 16.0 & 0.55 & 0.50 & 0.50 & Recip. \\
\hline $\mathrm{I} 90257 \times \mathrm{I} 30555$ & 9.75 & 6.00 & 18.5 & 9.07 & 1.00 & 3.00 & Recip. \\
\hline $\mathrm{I} 90257 \times \mathrm{I} 30572$ & 1.75 & 0.50 & 0.50 & 18.25 & 3.00 & -0.25 & Recip. \\
\hline I90257×I60142 & 5.00 & 0.75 & 7.0 & -3.54 & 3.0 & 0.50 & Recip. \\
\hline I90257×I63397 & 13.75 & -2.63 & 18.00 & 3.25 & 9.5 & 1.75 & Recip. \\
\hline $\mathrm{I} 4(2) 1425 \times 30001$ & 11.50 & -2.5 & 17.00 & -2.75 & 6.00 & 2.00 & Recip. \\
\hline $\mathrm{I} 4(2) 1425 \times \mathrm{I} 30555$ & 14.25 & 0.13 & 25.0 & 0.50 & 3.5 & 0.25 & Recip. \\
\hline $\mathrm{I} 4(2) 1425 \times \mathrm{I} 30572$ & 3.75 & 3.00 & 4.00 & 5.00 & 4.5 & 1.25 & Recip. \\
\hline $\mathrm{I} 4(2) 1425 \times \mathrm{I} 60142$ & 4.75 & 9.00 & 6.50 & -3.25 & 0.5 & 0.50 & Recip. \\
\hline I4(2) $1425 \times I 63397$ & 4.75 & 1.38 & 7.00 & -2.54 & 2.5 & 1.25 & Recip. \\
\hline I4(2) $1425 \times I 90257$ & 5.15 & 0.75 & 3.00 & 2.07 & 11.3 & 2.00 & Recip. \\
\hline Time- $8 \times 30001$ & 5.25 & $-5.38^{* *}$ & 9.50 & $-4.75^{* *}$ & 1.00 & $-5.00^{* *}$ & Recip. \\
\hline Time- $8 \times \mathrm{I} 30555$ & 5.25 & 2.25 & 6.00 & 3.52 & 4.50 & 2.25 & Recip. \\
\hline Time- $8 \times \mathrm{I} 30572$ & 29.50 & -0.25 & 29.5 & -5.53 & 29.50 & -1.75 & Recip. \\
\hline Time- $8 \times$ I60142 & 11.00 & $-8.88 * *$ & 21.5 & $-9.75^{* *}$ & 0.50 & $6.50 * *$ & Recip. \\
\hline Time-8×I63397 & 0.50 & 0.87 & 0.5 & 2.00 & 0.50 & 0.50 & Recip. \\
\hline Time-8×I90257 & 2.25 & 3.37 & 0.5 & 12.25 & 4.00 & -2.00 & Recip. \\
\hline Time- $8 \times$ I4(2) 1425 & 6.75 & 1.00 & 10.0 & 4.51 & 3.50 & -1.50 & Recip. \\
\hline Time- $9 \times 30001$ & 4.25 & 6.25 & 8.00 & 7.02 & 0.50 & 4.25 & Recip. \\
\hline Time- $9 \times 130555$ & 12.00 & 0.88 & 20.5 & 0.51 & 3.50 & -1.75 & Recip. \\
\hline Time-9×I30572 & 5.75 & 4.50 & 17.0 & 0.25 & 7.00 & 3.25 & Recip. \\
\hline Time-9×I60142 & 14.25 & $-14.00 * *$ & 25.5 & -3.75 & 3.00 & -1.50 & Recip. \\
\hline Time-9×I63397 & 8.50 & 4.13 & 15.5 & 5.52 & 0.50 & 2.75 & Recip. \\
\hline Time-9×I90257 & 16.00 & 1.07 & 20.5 & 8.50 & 11.50 & 0.50 & Recip. \\
\hline Time- $9 \times$ I4(2) 1425 & 12.25 & .13 & 24.0 & -1.54 & 0.50 & 2.25 & Recip. \\
\hline Time-9×TIME- 8 & 5.75 & 3.13 & 11.0 & 1.75 & 0.55 & 0.50 & Recip. \\
\hline SE (sii) & & 3.96 & & 5.29 & & 3.76 & \\
\hline SE (sij) & & 1.69 & & 2.22 & & 1.59 & \\
\hline SE (sii-sjj) & & 5.01 & & 6.57 & & 4.65 & \\
\hline SE (ii-skj) & & 5.90 & & 7.85 & & 5.55 & \\
\hline SE (ij-skj & & 5.69 & & 7.45 & & 4.96 & \\
\hline
\end{tabular}

*, ** Significantly different from zero at 0.05 and 0.01 probability levels respectively

*LSM = least Square means

The significant genotypes $\mathrm{X}$ environment interaction observed in the study are an indication of lack of stability of across environments in development of CAD symptoms. This suggests that parents including the crosses must be evaluated in more than one single environment in order to obtain precise genetic information required. The General Combining Ability (GCA) and the Specific Combining Ability (SCA) were found to be relatively important in determining progeny performance. The non-predominance of neither GCA nor SCA was further reflected by non-significant correlation between the parental means and their GCA effects, which indicates that progeny performance cannot be determine from parental performance per se. The significant female by male interaction also confirms the presence of non-additive components in the resistance of crosses to CAD. The ratio of additive variance to total genetic variance in a population is an indication of relative importance of both GCA and SCA in predicting progeny performance in resistance of cassava to CAD. The closer this ratio is to one the greater the chances of predicting progeny performance based on $\mathrm{GCA}^{[14,16] \text {. }}$ 
The significance of the contrast, parent vs crosses justifying the separation of parents and crosses before the iallel analysis was done. The GCA and SCA sum of squares accounted for 43.44 and $56.56 \%$ respectively of the variation among the crosses. This demonstrated that both additive and non-additives gene effects are also important in determining the expression of resistance to CAD in cassava even though the SCA contributed more.

The negative values of GCA effects of parental lines indicate a contribution towards resistance while positive values represent contribution towards susceptibility. The moderately resistant improved clone I63397, moderately susceptible improved I4 (2) 1425 and the susceptible local variety TIME-1 had significant and negative GCA effects in the diallel analysis showing their ability to transmit resistance. Among the susceptible lines, the high capability of I30572 to transmit susceptibility is notorious. From this findings the magnitude and sign of GCA effects of each parent is not generally in agreement with their individual performance per se. This indicated that initial selection of parents for hybrid combination might not largely be based on the disease reaction. The significance of maternal and reciprocal effects suggested that the variation observed in this experiment was not only due to direct genetic effects. Maternal effects originate from differences in cytoplasm usually DNA in replicating organelles such as mitochondria, or from differences in maternal environment provided to the developing embryos ${ }^{[16]}$ Genotype I30572 had a high significant effect towards susceptibility. Using this line as female parent in the hybrid combination will not allow the expression of resistance governed by nuclear genes. The significant of parents' means of squares in the diallel analysis showed that diverse variability occurred among the parents suggesting that African landraces and IITA improved germplasm could be a source of resistance to CAD.

The report of this study has significance implications for cassava breeding programs that seek to incorporate resistance to CAD. This is because in the diallel analysis, the additive effects as well as nonadditive genetic effects are desirable for resistance to CAD. Hence the progeny performance may not be based on the parent performance $\mathrm{sec}^{-1}$ is investigation emphasized the need to screen parents and crosses before their use in breeding suggesting that combining ability analysis based on progeny test data is useful in cassava breeding programme. Of course these conclusions are in agreements with the findings of ${ }^{[18,19]}$ who claimed that parents with high GCA effects did not necessarily produced hybrids with high SCA, but in contrast with the work of ${ }^{[20]}$.

\section{REFERENCES}

1. FAO, 2002. The global cassava development strategy and implement plan. Proceedings of validation forum on the global cassava development strategy. Vol: 2. Rome, 26-28 April, 2000.

2. Lozano, J.C., AC. Bellotti, J.A. Reyes, R.H. Howland, D. Leihner and J. Doll, 1981. Field Problems in Cassava. CIAT (Centro International de Agricultura Tropical), Cali Colombia, pp: 16-25.

3. Hahn, S.K., J.C.G. Isoba and T. Ikotun, 1989. Resistance breeding in root and tuber crops at International Institute of Tropical Agriculture, Ibadan. Nigeria. Crop Protection, pp: 147-168.

4. Muyolo, G., 1984. Studies on the interaction between Xanthomonas campestris p.v. manihotis Berthet and Bonder and Colletotrichum gloeosporioides f. sp manihotis (Chev) on cassava and its effects on yield. M. Phil. Thesis. University of Ibadan, Nigeria, pp: 130.

5. Makambila, C., 1987. Etude de L anthracnose du manoic (Manihot esculenta Crantz) et son agent pathogene Colletotrichum gloeosporioides (PENZ) f sp manihotis (Henn):These de Docteur Es science Naturelles a L Universite de Clermoont-Ferrand II pp: 493.

6. Fokunang, C.N., 1995. Evaluation cassava genotypes for resistance to anthracnose and other major disease through integrated control strategies. Ph. D Thesis. DeparTiment of Agriculture Biology, University of Ibadan, Nigeria, pp: 231.

7. Wydra, K. and W. Msikita, 1995. An overview of the present situation of cassava diseases in West Africa. In: Proceedings of the Sixth Triennial Symposium of the International Society for Tropical Root Crops-Africa Branch. 22-28th October, 1995, Lilogwe, Malawi, pp: 195-201.

8. Asiedu R., S.Y.C. Ng, K.V. Bai, I.J. Ekanayake, N.M.W. Wanyera, 1998. Genetic Improvement. In: Food Yams: Advances in Research, Orkwor, G.C., R. Asiedu and I.J. Ekanayake (Eds.). IITA and NRCRI, Ibadan, INigeria, pp: 63-104

9. Mahungu, N.H., A.G.O. Dixon and J.M. Mkumbira, 1994. Breeding cassava for multiple pest resisitance in Africa. Afri. Crop Sci. J., 2: 539-552. 
10. Boniebale, M., C. Guevara, A.G.O. Dixon, N.Q. Ng, R. Aseiedu and S.Y.C. Ng, 1997. Cassava. In: Bioderiversity in Trust: Conservation and use of Plant Genetic Resources in CGIAR Centers, Dominic F., S. Linda and S. Paul, (Eds.) Cambridge University Press, Cambridge, UK.

11. Ikotun, T. and S.K. Hahn, 1991. Screening Cassava cultivars for resistance to cassava anthracnose disease. A paper present at the International Society for Tropical Root Crops (ISTRC), African branch, held in Accra, Ghana.

12. Griffing, B., 1956. Concepts of general and specific combining ability in relation to diallel crossing systems. Aust. J. Biol. Sci., 9: 463-493.

13. Singh, R.K. and Chaudhary, B. D. (1977). Biometrical methods in quantitative genetic analysis. Kalyani Publisher. New Delhi, India.

14. Kang, M.S., 1994. Applied quantitative genetics. M.S. Kang Publisher Baton Rouge, pp: LA194.
15. Zhang, Z. and S.K. Kang, 1997. A SAS program for Griffing's Diallel analyses. Agron. J., 89: 176-182.

16. Baker, R.J., 1978. Issues in Diallel analysis. Crop Sci., 18: 533-536.

17 Borges, F.O.L., 1987. Diallel analysis of maize resistance to Sorghum downy mildew. Crop Sci., 27: 178-180.

18. Gaur, P.C., S.K. Pandey and S.V. Singh, 1993 Combining ability study in the development of potato hybrids suitable for processing. J indial Potato Assoc., 20: 144-149.

19. Sharma, Y.K., P.C. Katoch, S.K. Sharma and S.K. Chaudhary, 1998. Genetic ability in True potato seed populations. India Potato Assoc., 25: 33-38.

20. Mohammed Z.I. and A.K. Sultan, 2003. Line x tester analysis in true seed potato (Solanum tuberosum spp. tuberosum) Online J. Biol. Sci., 3: 674-680. 